Submission ID: 43870

\title{
Global Climate Change
}

I.I. Nesterov (West Siberian Division of A.A. Trofimuk IPGGG of the Siberian Branch of the RAS), V.I. Samitova* (West Siberian Division of A.A. Trofimuk IPGGG of the Siberian Branch of the RAS)

\section{SUMMARY}

In Geology, studied a wider range of measurement parameters, but most of them increases (decreases) under the influence of the moon, Sun and Galaxy in which Earth is situated. Therefore, in contrast to classical thermodynamics, and astrophysics made an attempt astronomical calculations to produce a new methodology using the parameters and processes of the past and what is happening on the Ground and its depths. 


\title{
Изменение глобального климата Земли
}

\author{
И.И. Нестеров (ЗСФ ИНГГ СО РАН), В.И. Самитова (ЗСФ ИНГГ СО РАН)
}

В астрофизике детально рассматривается вся информация по Звездам, Галактикам и Вселенной, получаемая в оптическом и близком к нему диапазонах электромагнитных взаимодействий. Законы Хаббла, Планка, Ньютона, Эйнштейна и др. основываются на фундаментальных единицах химии и физики, которые определяются по приборам установленных как на Земле, так и в космических аппаратах. В предлагаемой статье используется геологическая информация и выводятся на основе ее новые взаимодействия физических полей Земли с Космосом. В отечественной литературе впервые о связи геологических процессов с Космосом писал В.И. Вернадский.[2]

В геологии изучается более широкий спектр параметров измерения, но большинство их усиливается (уменьшается) под влиянием Луны, Солнца и Галактики, в которой находится планета Земля. Поэтому в отличие от классической термодинамики и астрофизики мы сделали попытку астрономические расчеты дополнительно производить по новой методологии с использованием параметров и процессов, происходивших и происходящих на Земле и ее недрах.

Существует распространенное убеждение, что имеется прямая связь между активностью Солнца и климатом на Земле. Еще более популярной является связь земного климата с положением Земли на солнечной орбите - это смена осени, зимы, весны и лета. Несомненно влияние на климат таких факторов как вращение Земли вокруг своей оси - ночью всегда прохладнее, чем днем.

Если ранжировать во времени и значимости показатели влияющие на климат Земли, то наиболее мелкой единицей являются «случайные» колебания температуры воздуха за счет облачности и ветра (первый порядок), затем следуют более постоянное влияние холодных и теплых течений океана (второй порядок). На третьем месте - вращение Земли вокруг своей оси (третий порядок), на четвертом месте - положение Земли на солнечной орбите (четвертый порядок). Но глобальные климатические катастрофы определяются положением Солнца с планетами на Галактической орбите (пятый порядок): когда меняются длительности суток и годов; среднегодовая температура водной поверхности океана; изменяется «радиус» Земли; магнитные и гравитационные характеристики, изменяется уровень океана - происходят наступления и отступления морей и океанов и др. глобальные явления.

По данным С.В.Авакяна [1] солнечные магнитные бури повторяются с периодичностью 11 лет с 1860-по 2012 год. При этом сменяется за указанное время 3 режима: (1790?)1865-1890 годы; 1890-1990 годы и 1990-2012(2090?) годы при одинаковой амплитуде в 30 единиц. Почти в строгом соответствии с той же частотой повторяемости (11 лет) происходит смена солнечных пятен, но амплитуда количества их постоянно меняется. Максимальная амплитуда зафиксирована в 1955-1965 годах (200 единиц), а минимальная - в 1890-1910 годах. Уменьшение частоты солнечных бурь и пятен в 1890-2010 годах совпадает с планетарным потеплением климата.

Вариации космических лучей зафиксированы со строгой периодичностью через каждые 11-12 лет с чередованием амплитуд 13 и 11 единиц. При этом положительные всплески приурочены к минимумам солнечных пятен и магнитных бурь. С погодными условиями эти вариации видимой связи не имеют, но их можно прогнозировать с большой точностью, чем другие параметры солнечной активности (рис.1). 


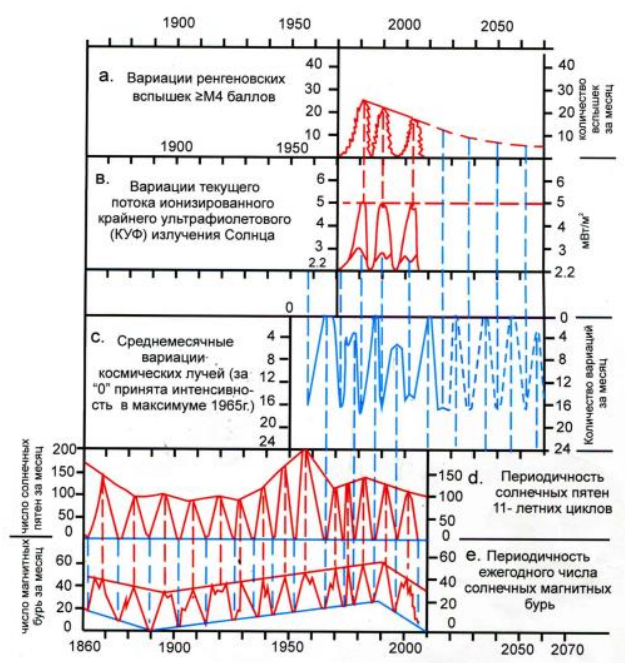

Рисунок 1 Основные параметры солнечного излучения (по данным С.В. Авакяна)

Показательны вариации потока ионизированного крайнего ультрафиолетового излучения Солнца и рентгеновских вспышек с интенсивностью более M 4 баллов. Максимумы и минимумы их совпадают и имеют периодичность 10-11 единиц, а так же совпадают с частотой солнечных магнитных бурь и пятен. Такая периодичность и совпадения максимумов и минимумов параметров, приведенных выше, в общем показывают отсутствие прямых связей их с глобальным потеплением климата Земли. Это позволило [1] прийти к выводу об отсутствии связи глобального потепления с активностью солнечного излучения.

В истории Земли за счет пересыщения $\mathrm{CO}_{2}$ в воде океанов выпадало в осадок громадное количество карбонатных пород. Общее их содержание в земной коре составляет $10^{15}$ т. Углекислый газ - это основа жизни на Земле. Большая концентрация $\mathrm{CO}_{2}$ в воздухе, это прежде всего, увеличение доли кислорода. Особое внимание при изучении баланса углерода в сферах Земли имеют исследования изотопного состава углерода, его магнитный момент и эволюция его в атмосфере и в изменении состава пород, а также передаче продуктам его переработки памяти о времени образования новой молекулы.

Время в истории Земли и Космоса переменно. Существует несколько параметров для определения времени, которое называют Ньютоновским, Хаббловским, Планковским, Галактическим, радиоактивным и др. В Ньютоновском времени сутки и год постоянны и, соответственно, равны 24 часа и 365 суток. Американский астроном Эдвин Хаббл в 1929 году за единицу времени взял математически неопределенную величину - «современное» для определения возраста Вселенной. Оно примерно равно 4000 мегапарсек (пк). 1 пк $\approx 3 \cdot 10^{18} \mathrm{~cm}$, или пк - расстояние, равное большой полуоси земной орбиты, расположенной перпендикулярно лучу под углом 1" (одна секунда). В 1929г. Э.Хаббл обнаружил красное смещение в спектрах ярких звезд далеких Галактик «Чем дальше находится Галактика с известным расстоянием, тем больше скорость ее удаления». Это явление названо законом «Хаббла», который вытекает из метрики Фридмана-Робертсона-Уокера.

Скорость вращения Галактик обычно максимальна на расстоянии нескольких килопарсек (Кпк) от их центра и дальше почти не меняется. По замерам многих астрофизиков параметр замедления (ускорения) имеет отрицательное значение. По нашим расчетам в конце четвертичного периода (через 22 млн. лет) Земля и окружающий Космос перейдут в систему сжатия. Если прошлое время обозначать с отрицательным знаком, а будущее положительным, то по закону Хаббла, окраины Вселенной сейчас находятся в режиме расширения с замедленным ускорением. Максимальная скорость вращения коррелируется массой диска Галактик и интегральной светимостью их. Если Галактики расположены в ближней зоне на расстоянии нескольких Мегапарсек, то расчеты их параметров ненадежны вследствие взаимодействия магнитных и гравитационных полей 
Академик П.П. Паренаго и И.Г. Яркин ввели понятие Галактического года с вращением Солнечной системы вокруг осевой зоны Галактики, состоящей из скоплений звезд, с вращением их по часовой стрелке. Солнечная система со всеми своими планетами вращается вокруг осевой зоны Галактики со скоростью на эллипсоидной орбите против часовой стрелки 250 км/сек. Определения параметров галактического года так же основано на классических определениях физики и поэтому требуют введения специальных поправок для повышения точности измерений с помощью специальных, в том числе космических приборов для оптических и радиоастрономических телескопов и специальных приемников электромагнитных и близких к ним волн.

До образования Солнечной системы и ее планет, спутников и астероидов нами предлагается ранжирование главных временных событий в жизни Космоса по хроонам аналогом геологических единиц времени. Кроме того, принципиально новым является разделение Галактик на этапы - расширения (разуплотнения), когда объем их увеличивается при сохранении массы и уплотняющийся, когда объем их уменьшается. Для первого этапа жизни Земли граница между этими двумя режимами предполагается в конце четвертичного периода через 22 млн. лет от 01.01.1900 года.

При модели жизни Вселенной от одного до другого «Большого Взрыва» необходимо обосновать причины смены знака. Предполагается, что такой причиной в жизни Вселенной и отдельных Галактик является появление антиматерии на внешней сфере их, когда электрон становится положительным, а протон - отрицательным.

Ньютоновское время в истории Земли, каждой индивидуальной Галактики и др. небесных тел переменно. Чешским исследователем 3. Кукал приводятся данные о том, что в скелете кораллов имеются суточные и годичные знаки того времени когда они жили. Нами построены графики изменения годов и суток в истории Земли, которые имеют линейную зависимость. Предположено по аналогии с законом Хаббла, что время стратонов Земли и хроонов в истории Космоса так же изменяются по линейному закону.

Возраст Земли нами определяется в 4687 млн. лет, а отдельные этапы ее истории определены по ярусам, периодам, эрам (галактическим годам) и эонам. По нашим расчетам через - 3275-4709 млн. от «точки» 00; 00.01.1900г. сутки будут равны 40.8 часов, а год - нулю. T.e. планета Земля в конце второго этапа жизни (первый этап - 4687 млн. лет) перестанет существовать и сольется или взорвется вместе с Солнцем.

После земных стратонов (ярусы, периоды, эры), (галактический год и эоны) выделены хрооны, протооны, галаоны и перион, которые были до образования Солнечной системы. Последний хроон равен времени от прошедшего «Большого Взрыва» до следующего. Это время равно 35.2 млрд. лет, из которых прошло $18.55 \cdot 10^{9}$ лет и прогнозируется следующий «Большой Взрыв через 16.65 млрд. лет.

От начала возникновения планеты Земля до окончания ее жизни с двумя режимами (растяжения и сжатия) полный цикл составляет 9,4 млрд. лет. Соответственно, от начала «Большого взрыва» был еще один этап возможного существования еще одной планеты типа Земли. До следующего «Большого взрыва» (через 16650 млн. лет) предполагается также два планетных этапа со средней длительностью каждого 8,3 млрд. лет.

Для северного полушария Земли положение апогалактия (8.59 Кпк) (завершение «зимнего» периода) и перигалактия $(7,12$ Кпк) - «летние» этапы на границе периодов в 23 галактическом году жизни Земли, которые, соответственно, приурочены к «зимнему» и «летнему» этапам жизни Земли. В «зимний» этап в зоне циркульполярного круга происходило резкое похолодание с образованием ледяных покровов толщиной до 2-3 км. При таянии этих покровов, они двигались с севера на юг и с запада на восток, оставляя за собой глыбы коренных пород, размером до (2-3) х (0.5-1)км и толщиной до 50-100м.

В 2010 году обнаружены реликтовые ледниковые породы на р.Исеть к югу от г.Тюмени. В настоящее время Солнечная система и Земля двигаются на орбите 23 галактического года к перигалактию («лето») и достигнут его через 22 млн. лет. Что ожидает Землю в «летний» этап можно предполагать по ближайшему в прошлом «летнему» периоду.

В.А. Захаровым и др. по древним белемнитам киммериджа в районе пос. Няксимволь на севере Тюменской области определена температура приповерхностных вод ЗападноСибирского палеоморя по замерам 18 изотопа кислорода. По этим данным нами построена 
карта изотерм территории современного Ледовитого океана, которые достигли $+19+20^{\circ} \mathrm{C}$. (рис.2)

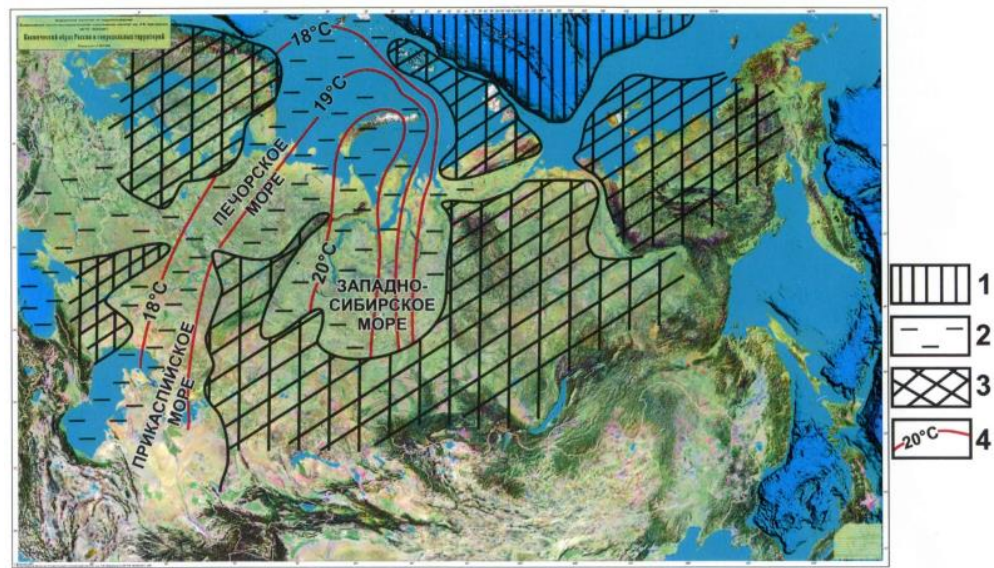

Рисунок 2 Предполагаемые температуры приповерхностных водных бассейнов на границе юры и мела России (по материалам В.А. Захарова и др.)

1.Присклоновое море с океанической корой; 2. Шельфовые моря; 3.Суша; 4.Термоизолинии поверхностных вод

Эти температуры подтверждаются составом спор и пыльцы из пород верхней юры и неокома нижнего мела. Намечающее изменение теплого течения Гольфстрим в сторону Гренландии, обогревающего север Европы, может не привести к климатической катастрофе изза глобального потепления, связанного с приближением Солнечной системы к «летнему» этапу на орбите 23 галактического года. Но уже сейчас нужно готовиться к глобальному потеплению.

\section{Библиография}

1. С.В. Авакян. Роль активности Солнца в глобальном потеплении. Вестник РАН, Москва, Наука, №5, т. 83. 2013. с. 425-436.

2. В.И. Вернадский. Избранные сочинения. - М.: Изд. АН СССР. 1960. Т. 5. с. 423.

3. И.А.Зотиков. Тепловой режим ледника Антарктиды. Доклады комиссии 1961г. М.:1962.

4. В.М.Котляков, В.Я.Липенков, Н.И.Васильев. Глубокое бурение в Центральной Антарктиде и проникновение в подледное озеро Восток. Вестник РАН.2013.т.83.№7.c.591-605.

5. И.И. Нестеров. Время в истории Земли. Изд. ТюмГНГУ. Ж. Нефть и Газ, 1999. №2.

6. И.И. Нестеров. Геокатастрофы в истории Земли и Космоса. - Ж. Горные ведомости, №2(21). - c. 16 .

7. И.И. Нестеров. Хронография и хроностратиграфия. - Тюмень, 2012. - Ж. Горные ведомости. - №6(92). - с. 30-59.

8. П.П. Паренаго. О гравитационном потенциале Галактики. Астрономический журнал, 1952. T. 29, №3.

\section{References}

1. S. V. Avakyan. The role of solar activity in global warming. Bulletin of the Russian Academy of Sciences, Moscow, Nauka, No. 5, T. 83. 2013. p. 425-436.

2. V. I. Vernadsky. Selected writings. - M.: Publishing House. USSR ACADEMY OF SCIENCES. 1960. Vol. 5. S. 423.

3. I. A. Zotikov. The thermal regime of the glacier, Antarctica. The reports of the Board 1961. M.:1962.

4. V. M. Kotlyakov, V. Lipenkov, N. And.Vasiliev. Deep drilling in Central Antarctica and the penetration of the subglacial lake Vostok. Bulletin of the Russian Academy of Sciences.2013.t.83. No. 7. p. 591-605. 


\section{EAGE}

5. I. I. Nesterov. Time in Earth's history. Ed. TSOGU. J. Oil and Gas, 1999. No. 2.

6. I. I. Nesterov. Geokatastrofy in the history of the Earth and the Cosmos. - J. Mountain Gazette, №2 $(21)$. - p. 16.

7. I. I. Nesterov. Chronographia and chronostratigraphy. - Tyumen, 2012. - J. Mountain Gazette. No. 6(92). - p. 30-59.

8. P. P. Parenago. About the gravitational potential of the Galaxy. The astronomical journal, 1952. Vol. 29, No. 3. 